\title{
Relationship between Bone Density and Biochemical Markers of Bone among Two Groups Taking Carbamazepine and Sodium Valproate for Epilepsy in Comparison with Healthy Individuals in Yazd
}

\author{
Abolghasem Rahimdel ${ }^{1}$, Ali Dehghan ${ }^{2}$, Mahboubeh Abolhassani Moghadam ${ }^{3}$, Ali Mellat Ardekani ${ }^{1}$
}

${ }^{1}$ Neurologist, Associated Professor, Neurology Department, Shahid Sadoughi Hospital, Yazd University of Medical Science, Yazd, Iran

${ }^{2}$ Rheumatologist, Assistant Professor, Internal Medicine Department, Shahid Sadoughi Hospital, Yazd University of Medical Science, Yazd, Iran

${ }^{3}$ Medical Student, Shahid Sadoughi Hospital, Yazd University of Medical Science, Yazd, Iran

\section{Type of article: Original}

\begin{abstract}
Introduction: Chronic antiepileptic therapy has been associated with metabolic bone diseases including osteomalacia and osteoporosis. The aim of this study was to determine frequency of changes in biochemical and bone mineral density (BMD) in adults receiving valproaic acid (VPA) \& carbamazepine (CBZ).

Methods: In a cross sectional study evaluating adults (age 20-50 y) epileptic patients receiving valproic acid or carbamazepine for at least 2 years. This study was conducted from May 2014 to May 2015 in Shahid Sadoughi Hospital of Yazd University of Medical Science, Yazd, Iran. Bone metabolism was evaluated by measurement of serum calcium (Ca), phosphorus (P), alkaline phosphatase (ALP) and parathormone hormone (PTH), BMD at lumbar and femoral measured by dual energy X ray absorptiometry (DXA). SPSS software (version 18) was used for data analysis. The t-test was used for quantitative data, and the chi-squared test was used for the qualitative variables.

Results: Eighty two epileptic patients (mean age: $31.67 \pm 10.69$ year) treated with either carbamazepine $(\mathrm{n}=41)$ or valproate sodium $(n=41)$ were studied. Normal serum $\mathrm{Ca}$ and $\mathrm{P}$ levels were observed in $98.8 \%$ and $97.6 \%$ of patients respectively. Serum ALP and PTH were normal in $97.6 \%$ and $97.6 \%$ of patients. Means of Ca and P in CBZ group were significantly lower than VPA group (Ca: 9.02 vs. 9.1 , p-value: 0.03 and P: 3.54 vs. 3.76 pvalue: 0.004 ). BMD values at lumbar spine were not significant in either group (T. score CBZ: $-0.43 \pm 0.744$ vs. T. score VPA: $-0.615 \pm 0.904$ and p-value: 0.333 ) and were significantly higher than Iranian normal population BMD value at femoral neck in CBZ group was lower than VPA group (T. score CBZ: $-0.707 \pm 0.896$ vs. T. score VPA: $-0.297 \pm 0.850$ p-value: 0.04 ). Dosage of CBZ and VPA did not correlate with BMD and biochemical parameters. Duration of CBZ use had correlation with increased ALP and duration of VPA use had correlation with decreased BMD in adult patients.

Conclusion: long term anti-epileptic drug treatment either with CBZ and VPA which has unknown effects on skeletal mineralization and induces a state of decreased bone mineral density BMD values at femoral neck were significant in CBZ group Therefore regular screening for monitoring of biochemical markers of bone turnover and BMD with DXA during the treat period is recommended. In addition, Ca supplement could be considered for all patients with epilepsy upon initiation of CBZ and VPA therapy.

Keywords: Epilepsy, Sodium Valproate, Carbamazepine, Bone Density
\end{abstract}

\section{Introduction}

Epilepsy is a neurological disease, which has affected approximately 45 million people worldwide (Prevalence of epilepsy is $1 \%-0.65 \%$ ). Non-barbiturate medications such as carbamazepine and sodium valproate are used as the first line of treatment for proper and long-term control of seizures (1). Carbamazepine is an anticonvulsant drug,

\section{Corresponding author:}

Associate Professor Dr. Ali Mellat Ardekani, Neurology Department, Shahid Sadoughi Hospital, Yazd University of Medical Science, Yazd, Iran, Tel: +98.9133514543, Email: ali_mellat@yahoo.com

Received: December 12, 2015, Accepted: February 16, 2016, Published: November 2016

iThenticate screening: March 01, 2016, English editing: October 09, 2016, Quality control: November 04, 2016

(c) 2016 The Authors. This is an open access article under the terms of the Creative Commons Attribution-NonCommercialNoDerivs License, which permits use and distribution in any medium, provided the original work is properly cited, the use is non-commercial and no modifications or adaptations are made. 
which is primarily used for treatment of seizures, bipolar disorders and trigeminal neuralgia. Side effects of this medication are dizziness, headache, cardiac arrhythmias, blurred vision, diplopia, reduction in red blood cells and platelets, liver malfunction and aplastic anemia in rare cases. In addition, carbamazepine may exacerbate already existing hypothyroid. Due to following complications, it is recommended that patients undergo blood and thyroid tests 3-4 times annually for follow up. It is also reported that carbamazepine can be a cause of hearing loss (2). Sodium valproate was used as a broad-spectrum anticonvulsant medication to treat epilepsy. This drug has dosedependent side effects. Indigestion, weight gain, fatigue, dizziness, peripheral edema, hair loss, drowsiness and tremor could be noted as the most common side effects (3). In addition to known side effects of this drug, there is growing evidence that antiepileptic drugs lead to bone destruction and cause such bone diseases as osteomalacia, osteopenia and osteoporosis. $(4,5)$. Several theories have been suggested about the mechanism of antiepileptic drugs for inducing bone diseases but none of the suggested theories alone can explain all findings. The prevailing explanation lies in the fact that such antiepileptic drugs as carbamazepine induce P450 cytochrome hepatic enzyme, which increases conversion of vitamin D to inactive metabolites. Biologically, inactive vitamin D reduces intestinal calcium absorption, which causes hypocalcemia and eventually increases secondary hyperparathyroidism and parathyroid hormone, which reduces levels of phosphorus while increasing calcium and alkaline phosphatase. Hyperparathyroidism increases metabolism of bone calcium storage and bone graft harvesting while reducing cortical bone. Since sodium valproate inhibits P450 cytochrome hepatic system, this theory cannot explain the effects of valproate (6). Although limited studies were conducted on this issue in Iran, these studies did not exclusively determine the relationship of bone health and administration of carbamazepine and sodium valproate with bone densitometry techniques.

\section{Material and Methods}

\subsection{Participants}

This was a cross sectional study, which was conducted on the individuals who visited neurology clinic. Among these individuals, 82 patients with generalized or partial epilepsy who were between 20 and 50 years old and treated with therapeutic doses of carbamazepine or sodium valproate for more than two years were reviewed and studied. The sample was simply selected from the individuals who visited neurology clinic. According to a similar study (9) in which L2 standard deviation was equal to $0.16,41$ individuals were required for each group.

\subsection{Eligibility criteria and data collection}

Among these individuals, 82 patients with generalized or partial epilepsy who were between 20 and 50 years old and treated with therapeutic doses of carbamazepine or sodium valproate for more than 2 years were reviewed and studied. A check list was designed for all patients, which included such demographic information as age, gender, type of seizure, type of medication, history of trauma, underlying disease, positive familial history and simultaneous intake of other medications. Inclusion criteria for the project was the patients with generalized or partial epilepsy who were between 20 and 50 year's old and received therapeutic doses of carbamazepine or sodium valproate (at least $400 \mathrm{mg}$ ) for more than 2 years as a mono therapy. Exclusion criteria: Rheumatoid arthritis and other bone diseases, hypothyroidism or hyperthyroidism, parathyroid and adrenal diseases, diabetes, chronic renal diseases, end-stage liver failure and cancer and a history of intake of such medications as corticosteroid, calcium, vitamin D and chemotherapy drugs, a history of trauma and fractures. In addition, the patients took the drugs made in Iran. The two groups were homogenized in terms of age and gender. For eligible individuals, biochemical markers of bone consisting of calcium, phosphorus, alkaline phosphatase and parathyroid hormone were evaluated. In addition, femoral and lumbar bone density were measured using dual-energy X-ray absorptiometry (DXA) with a Hologic Device and Explorer Model. The measurements were expressed as mineralization (g) divided by the scanned area (square centimeter), which were provided as a densitometry index as T. score (the standard deviation below peak bone mass) for all the individuals. T. score evaluation was accepted as osteopenia or osteoporosis [based on definitions of the World Health Organization (WHO), a T. score between (-1) and (-2.5) is defined as osteopenia and a T. score less than $(-2.5)$ is referred to as osteoporosis]. All clinical tests were carried out in a reference center. Biochemical markers of the individuals were evaluated with respect to a normal range. Moreover, bone densitometry of the patients was compared with bone densitometry of Iranian healthy population. The data relevant to Iranian healthy population was extracted from an article entitled as bone density among a selected group of Iranian healthy population, which was investigated by Akbarian et al. in 1996 (22). In the former study, 218 individuals were randomly selected from 6,600 healthy people in different parts of Iran. Densitometry of lumbar and femoral bones were measured based on grams per square centimeter. The difference with hologic standards was also measured. It was shown that bone densities in lumbar and femoral bones of the selected individuals were lower than the desired hologic standards in both genders. 


\subsection{Data analysis}

The collected data was logged into SPSS Version 17 (SPSS Inc., Chicago, Illinois, USA) and analyzed using Independent-samples t-test and Chi-Square test.

\section{Results}

In this study 41 epileptic patients taking carbamazepine and 41 other epileptic patients taking sodium valproate for epilepsy were selected. In addition, 33 (40.2\%) patients were males and 49 (59.8\%) were females. Frequency of gender in the two groups can be observed in Table 1. Mean age of the patients was $31.67 \pm 10.69$ years old. Mean age of the patients in carbamazepine group was $31.5 \pm 8.49$ and mean age of the patients in sodium valproate group was $31.83 \pm 12.63$. According to independent $t$-test, there was no statistically significant difference between the two groups $(\mathrm{p}=0.894)$. Mean duration of disease in patients was $8.16 \pm 4.94$ years. Mean duration of disease in carbamazepine group was $8.68 \pm 4.84$ years and $7.63 \pm 5.04$ in sodium valproate group. No significant difference was observed between the two groups $(\mathrm{p}=0.340)$. Mean calcium, phosphorus, alkaline phosphatase and PTH levels in the two groups are shown in Table 2.

Table 1. Distribution of gender in the drug groups

\begin{tabular}{|l|l|l|l|}
\hline Drug & Male & Female & p-value \\
\hline Carbamazepine & $19(46.3 \%)$ & $22(53.7 \%)$ & 0.260 \\
\cline { 1 - 3 } Sodium Valproate & $14(34.1 \%)$ & $27(65.9 \%)$ & \\
\hline
\end{tabular}

Table 2. Mean of calcium, phosphor, alkalin phosphatase, paratormone, lumbar bone mineral density, T. score, and femoral bone density in two groups

\begin{tabular}{|l|l|l|l|l|l|l|l|}
\hline \multirow{2}{*}{ Variable } & \multicolumn{2}{l|}{ Carbamazepine } & \multicolumn{2}{l|}{ Sodium Valproate } & \multicolumn{2}{l|}{ Total } & \multirow{2}{*}{-value } \\
\cline { 2 - 8 } & Mean & SD & Mean & SD & Mean & SD & \\
\hline Calcium & 9.02 & 0.16 & 9.1 & 0.18 & 9.06 & 0.17 & 0.03 \\
\hline Phosphor & 3.54 & 0.25 & 3.76 & 0.41 & 3.65 & 0.35 & 0.004 \\
\hline Alkalin phosphatase & 169.44 & 40.73 & 165.56 & 94.48 & 167.5 & 72.33 & 0.81 \\
\hline Paratormone & 30.57 & 8.27 & 32.05 & 13.30 & 31.31 & 11.03 & 0.547 \\
\hline Lumbar bone mineral density & 1.001 & 0.075 & 0.981 & 0.103 & 0.991 & 0.9 & 0.318 \\
\hline T. score & -0.437 & 0.744 & -0.615 & 0.904 & -0.53 & 0.82 & 0.333 \\
\hline Femoral bone density & 0.796 & 0.116 & 0.857 & 0.102 & 0.722 & 0.113 & 0.031 \\
\hline T. score & -0.707 & 0.896 & -0.297 & 0.850 & -0.51 & 0.89 & 0.041 \\
\hline
\end{tabular}

The results showed that mean calcium and phosphorus levels were statistically significant in the two groups $(p<0.05)$. Mean calcium and phosphorus levels were lower in carbamazepine group than sodium valproate group. However, no statistically significant difference was observed in alkaline phosphatase and PTH levels between the two groups ( $>0.05)$. Calcium, phosphorus, alkaline phosphatase and PTH levels among the two groups with respect to a normal range are shown in the Table 2 . The results showed that more than $97 \%$ of patients were within normal range in terms of all biochemical markers. No significant difference was observed between carbamazepine and sodium valproate groups $(\mathrm{p}>0.05)$. Mean lumbar bone density and $\mathrm{T}$. score in the two groups are shown in Table 2 . The results showed no significant difference in mean lumbar bone density and $\mathrm{T}$. score among the two groups $(p>0.05)$. No significant difference was observed between the two groups $(p>0.05)$. A significant difference was observed between mean lumbar bone density of patients $(0.991 \pm 0.09)$ and mean lumbar bone density of Iranian healthy individuals $(0.928 \pm 0.103)(\mathrm{p}<0.001)$. Mean lumbar bone density of the patients was higher than healthy individuals. Mean femoral bone density and $\mathrm{T}$. score are given in Table 2. The results showed a significant difference in mean femoral bone density and $\mathrm{T}$. score in the two groups $(\mathrm{p}<0.05)$. Mean femoral bone density in carbamazepine group was lower than sodium valproate group. No significant difference was observed between mean femoral bone density of the patients $(0.822 \pm 0.113)$ and normal femoral bone density $(0.827 \pm 0.051)(p=0.725)$. No significant difference was also observed between mean femoral bone density in carbamazepine group $(0.796 \pm$ $0.116)$ and normal group $(0.846 \pm 0.045)(\mathrm{p}=0.02)$. A significant difference was observed between mean femoral bone density $(0.851 \pm 0.102)$ and normal group $(0.806 \pm 0.048)(\mathrm{p}=0.01)$ [Note: mean femoral bone density was lower in carbamazepine group than normal group while higher in sodium valproate group than normal group]. Length of treatment with carbamazepine and sodium valproate is shown in Table 3 . The contents of Table 4 shows a significant relationship between increased length of treatment with carbamazepine and alkaline phosphatase level $(\mathrm{p}<0.05)$. 
http://www.ephysician.ir

Table 3. Duration of drug use in each group

\begin{tabular}{|l|l|l|l|}
\hline Duration of drug use & Carbamazepine & Sodium Valproate & Total \\
\hline 2-5 years & $13(31.7 \%)$ & $18(43.9 \%)$ & $31(37.8)$ \\
\hline 6-8 years & $9(22 \%)$ & $10(24.4 \%)$ & $19(32.2)$ \\
\hline More than 9 years & $19(46.3 \%)$ & $13(31.7 \%)$ & $32(39 \%)$ \\
\hline Total & $41(100 \%$ & $41(100 \%)$ & $82(100 \%)$ \\
\hline
\end{tabular}

Table 4. Relation between duration of drug use and bone markers

\begin{tabular}{|c|c|c|c|c|c|c|c|}
\hline \multirow{2}{*}{\multicolumn{2}{|c|}{ Variable and time duration (year) in years }} & \multicolumn{2}{|c|}{ Carbamazepine } & \multirow[t]{2}{*}{ p-value } & \multicolumn{2}{|c|}{ Sodium Valproate } & \multirow[t]{2}{*}{ p-value } \\
\hline & & Mean & SD & & Mean & SD & \\
\hline \multirow[t]{4}{*}{ Calcium } & $2-5$ & 9.38 & 0.1121 & \multirow[t]{4}{*}{0.831} & 9.094 & 0.1514 & \multirow[t]{4}{*}{0.62} \\
\hline & $6-8$ & 9.033 & 0.1581 & & 9.220 & 0.221 & \\
\hline & $>9$ & 9.005 & 0.1929 & & 9.038 & 0.1805 & \\
\hline & Total & 9.022 & 0.1605 & & 9.107 & 0.1876 & \\
\hline \multirow[t]{4}{*}{ Phosphor } & $2-5$ & 3.523 & 0.3113 & \multirow[t]{4}{*}{0.826} & 0.822 & 0.337 & \multirow[t]{4}{*}{0.061} \\
\hline & $6-8$ & 3.511 & 0.3100 & & 0.580 & 0.3957 & \\
\hline & $>9$ & 3.568 & 0.1945 & & 0.892 & 0.4536 & \\
\hline & Total & 3.541 & 0.2569 & & 0.768 & 0.4101 & \\
\hline \multirow[t]{4}{*}{ Alkalin phosphatase } & $2-5$ & 156 & 28.888 & \multirow[t]{4}{*}{0.016} & 191.83 & 139.299 & \multirow[t]{4}{*}{0.296} \\
\hline & $6-8$ & 148.78 & 33.003 & & 146.50 & 12.695 & \\
\hline & $>9$ & 188.42 & 43.847 & & 143.85 & 17.339 & \\
\hline & Total & 169.44 & 40.734 & & 165.56 & 98.488 & \\
\hline \multirow[t]{4}{*}{ Paratormone } & $2-5$ & 25.488 & 6.9573 & \multirow[t]{4}{*}{0.05} & 31.866 & 12.8090 & \multirow[t]{4}{*}{0.657} \\
\hline & $6-8$ & 30.909 & 7.50 & & 29.260 & 11.0578 & \\
\hline & $>9$ & 34.22 & 7.63 & & 34.477 & 15.9166 & \\
\hline & total & 30.57 & 8.27 & & 13.058 & 13.3086 & \\
\hline \multirow{4}{*}{$\begin{array}{l}\text { Femoral } \\
\text { Bone density }\end{array}$} & $2-5$ & 0.85715 & 0.11604 & \multirow[t]{4}{*}{0.062} & 0.9207 & 0.82859 & \multirow[t]{4}{*}{0.000} \\
\hline & $6-8$ & 0.78356 & 0.067 & & 0.7775 & 0.10 & \\
\hline & $>9$ & 0.76 & 0.123 & & 0.8092 & 0.055 & \\
\hline & total & 0.796 & 0.11 & & 0.857 & 01028 & \\
\hline \multirow[t]{4}{*}{ T. score } & $2-5$ & -0.3 & 0.7059 & \multirow[t]{4}{*}{0.80} & 0.188 & 0.6432 & \multirow[t]{4}{*}{0.002} \\
\hline & $6-8$ & -0.644 & 0.6616 & & -0.920 & 0.9211 & \\
\hline & $>9$ & -1.061 & 1.017 & & -0.482 & 0.625 & \\
\hline & Total & -0.707 & 0.8962 & & -0.291 & 0.8592 & \\
\hline \multirow[t]{4}{*}{ Lumbar bone mineral density } & $2-5$ & 1.015 & 0.822 & \multirow[t]{4}{*}{0.501} & 1.02 & 0.08 & \multirow[t]{4}{*}{0.027} \\
\hline & $6-8$ & 1.013 & 0.0529 & & 0.96630 & 0.069 & \\
\hline & $>9$ & 0.986 & 0.079 & & 0.929 & 0.133 & \\
\hline & total & 1.0016 & 0.074 & & 0.9815 & 0.1038 & \\
\hline \multirow[t]{4}{*}{ T. score } & $2-5$ & -0.308 & 0.743 & \multirow[t]{4}{*}{0.208} & -0.217 & 0.7778 & 0.036 \\
\hline & $6-8$ & -0.167 & 0.7018 & & -0.830 & 1.2065 & \\
\hline & $>9$ & -0.653 & 0.7396 & & -1.000 & 0.584 & \\
\hline & Total & -0.437 & 0.7446 & & -0.615 & 0.9046 & \\
\hline
\end{tabular}

However, other biochemical markers of bone had no significant relationship with increased length of treatment. Table 4 shows the relationship between bone density and length of treatment with carbamazepine. No significant relationship was found between these two factors $(\mathrm{p}>0.05)$. Table 4 shows the relationship between biochemical markers of bone and length of treatment with sodium valproate. No significant relationship was observed between these two factors $(p>0.05)$. Table 4 shows the relationship between bone density and length of treatment with sodium valproate. A significant relationship was observed between lumbar bone density $(p=0.02)$ and length of treatment with sodium valproate as well as femoral bone density and length of treatment with sodium valproate $(\mathrm{p}=$ 0.05). Table 5 shows the relationship between biochemical markers of bone and dose of medication. No significant relationship was found between these two factors $(\mathrm{p}>0.05)$. Table 5 shows the relationship between bone density and dose of medication. No significant relationship was observed between these two factors among all patients. 
However, a significant relationship was observed between T. score of femoral bone density and dose of sodium valproate.

Table 5. Relation between dose of drug and bone markers

\begin{tabular}{|c|c|c|c|c|c|c|c|}
\hline \multirow{2}{*}{\multicolumn{2}{|c|}{ Variable and dose duration in $\mathrm{mg}$}} & \multicolumn{2}{|c|}{ Carbamazepine } & \multirow[t]{2}{*}{ p-value } & \multicolumn{2}{|c|}{ Sodium Valproate } & \multirow[t]{2}{*}{ p-value } \\
\hline & & Mean & SD & & Mean & SD & \\
\hline \multirow[t]{2}{*}{ Calcium } & $400 \mathrm{mg}$ & 9.01 & 0.172 & \multirow[t]{2}{*}{0.81} & 9.08 & 0.169 & \multirow[t]{2}{*}{0.48} \\
\hline & upper 400 & 9.02 & 0.143 & & 9.15 & 0.224 & \\
\hline \multirow[t]{2}{*}{ Phosphor } & $400 \mathrm{mg}$ & 3.55 & 0.247 & \multirow[t]{2}{*}{0.71} & 3.86 & 0.463 & \multirow[t]{2}{*}{0.08} \\
\hline & upper 400 & 3.52 & 0.228 & & 3.58 & 0.221 & \\
\hline \multirow[t]{2}{*}{ Alkalin phosphatase } & $400 \mathrm{mg}$ & 166.19 & 39.64 & \multirow[t]{2}{*}{0.85} & 172.08 & 118.52 & \multirow[t]{2}{*}{0.157} \\
\hline & upper 400 & 175.7 & 43.36 & & 152.43 & 13.00 & \\
\hline \multirow[t]{2}{*}{ Paratormone } & $400 \mathrm{mg}$ & 31.48 & 9 & \multirow[t]{2}{*}{0.132} & 32.36 & 14.881 & \multirow[t]{2}{*}{0.105} \\
\hline & upper 400 & 29 & 6.82 & & 32.34 & 10.373 & \\
\hline \multirow{2}{*}{$\begin{array}{l}\text { Femoral } \\
\text { Bone density }\end{array}$} & $400 \mathrm{mg}$ & 1.01 & 0.088 & \multirow[t]{2}{*}{0.207} & 0.933 & 0.106 & \multirow[t]{2}{*}{0.251} \\
\hline & upper 400 & 0.986 & 0.041 & & 1.013 & 0.980 & \\
\hline \multirow[t]{2}{*}{ T. score } & $400 \mathrm{mg}$ & 0.369 & 0.833 & \multirow[t]{2}{*}{0.264} & -0.733 & 3.938 & \multirow[t]{2}{*}{0.368} \\
\hline & upper 400 & -0.553 & 0.566 & & -0.336 & 0.828 & \\
\hline \multirow[t]{2}{*}{ Lumbar bone mineral density } & $400 \mathrm{mg}$ & 0.804 & 0.117 & \multirow[t]{2}{*}{0.697} & 0.855 & 0.117 & \multirow[t]{2}{*}{0.624} \\
\hline & upper 400 & 0.781 & 0.118 & & 0.842 & 0.082 & \\
\hline \multirow[t]{2}{*}{ T. score } & $400 \mathrm{mg}$ & -0.581 & 0.892 & \multirow[t]{2}{*}{0.336} & -0.343 & 0.990 & \multirow[t]{2}{*}{0.564} \\
\hline & upper 400 & -0.927 & 0.890 & & -0.250 & 0.616 & \\
\hline
\end{tabular}

\section{Discussion}

Epilepsy refers to repeated seizures without any stimulating factor due to abnormal neuronal depolarization, which causes a series of neurological signs and symptoms $(1,2)$. Literature has shown that about 45 million people have epilepsy worldwide. Proper control of seizures helps the patients to live without complications (3). Carbamazepine and sodium valproate are effective drugs used to control generalized tonic-clonic and partial seizures $(7,8)$. In addition to known side effects of these drugs, there is significant evidence that antiepileptic drugs can affect bone metabolism and cause osteoporosis (9). The following mechanisms are cited as effects of antiepileptic drugs on bone metabolism:

1) Increased inactive form of vitamin $\mathrm{D}$ due to induction of $\mathrm{P} 450$ cytochrome microsomal hepatic enzyme (by carbamazepine)

2) Accelerated bone metabolism (by carbamazepine and sodium valproate)

3) Inhibiting normal effect of parathyroid hormone (PTH) on bone metabolism (sodium valproate)

4) Interfering with normal metabolism of vitamin $\mathrm{K}$ (carbamazepine) (1)

The present study investigated the effects of carbamazepine and sodium valproate on bone metabolism at two levels of lumbar and femoral BMD (bone mineral density) as well as bone biochemical markers among epileptic patients. In various studies, increased loss of calcium and alkaline phosphatase and parathyroid hormone (PTH) were addressed as bone metabolism disorder (1). In this study, level of calcium in $98.8 \%$ of patients was within normal range. Moreover, phosphorus level of $97.6 \%$ of patients was within normal range. In total, mean calcium and phosphorus levels were within normal range in all patients. Calcium level was also within normal range among 97.6 $\%$ of the patients taking carbamazepine. Phosphorus levels were also within normal range among $100 \%$ of the patients taking carbamazepine. Calcium level was within normal range among $100 \%$ of patients taking sodium valproate. Phosphorus level was within normal range among $95.1 \%$ of the patients taking sodium valproate. It should be noted that normal serum calcium and phosphorus levels were reported in many previous studies. Ashrafi conducted a study on children treated with anti-epileptic drugs in Tehran in 2005 (1). The results were in line with those obtained in this study. In the former study, calcium level was within normal range among $96.6 \%$ of patients and phosphorus level was within normal range among $93.3 \%$ of patients. Furthermore, mean calcium and phosphorous levels were within normal range among the two groups taking carbamazepine and sodium valproate. Ashjazadeh et al. conducted a study on adult patients with long-term treatment with antiepileptic drugs in 2009 (10). Mean calcium and phosphorus levels were within normal range among the patients taking such anticonvulsant drugs as carbamazepine and sodium valproate. Alberto Verotti et al.(11) examined the effect of carbamazepine on bone metabolism in childhood in 2002. They reported that calcium and phosphorus levels were within the normal range. 
Babayi Jit et al. conducted a similar study on children in 2006 (12). Decreased calcium and phosphorus levels were observed in none of the patients. Triantafilo et al. studied long-term effects of sodium valproate on bone metabolism among adults in 2009(8), and calcium and phosphorus levels were within normal range. In contrast, several studies have reported loss of calcium and phosphorus. Acoyte et al. conducted a study on 31 children who were between 7 and 16 years old in 2004 (9). They reported $17.6 \%$ cases of hypocalcemia and $35.3 \%$ cases of hypophosphatemia in the group receiving carbamazepine. They also reported $25 \%$ cases of hypocalcemia and $50 \%$ cases of hypophosphatemia in the group receiving sodium valproate. Small statistical population, age and gender can be noted as the reasons for the difference between the results of the former study and all other studies. The patients were between 7 and 16 years old in the former study. Given that maximal amount of bone mineral accrued within bone and ossification accelerates during childhood, the need for calcium and phosphorus increases in this period. Thereby, the difference can be attributed to difference in age. In this study, a statistically significant difference was observed between calcium and phosphorus in the two groups. Calcium and phosphorus levels were significantly lower within a normal range in carbamazepine group (9.02) than sodium valproate group (9.1). Ashrafi reported 9.4 calcium level in carbamazepine group and 9.58 calcium level in sodium valproate in 2005 (1). In the former study, calcium level was significantly lower in carbamazepine group than sodium valproate group. However, phosphorus levels were equal in the two groups (4.53 vs. 4.51). Babayi Jit showed no significant relationship between two carbamazepine and sodium valproate groups in terms of calcium and phosphorus levels (13). Kim also showed no significant difference between calcium and phosphorus levels (14). As was observed in the above-mentioned studies, no significant difference was observed in calcium and phosphorus levels between the two groups. In this study, a significant difference was observed in calcium and phosphorus levels between the two groups. However, the difference was not clinically significant.

Alkaline phosphatase was within normal range among $97.6 \%$ of patients ( $100 \%$ of patients taking carbamazepine and $95.1 \%$ of patients taking sodium valproate). Alkaline phosphatase was above normal range among $2.4 \%$ of patients. Furthermore, PTH was within normal range among $97.6 \%$ of patients $(100 \%$ of patients taking carbamazepine and $95.1 \%$ of patients taking sodium valproate). Moreover, PTH was above normal range among $1.2 \%$ of patients and below normal range among $1.2 \%$ of patients. In general, mean PTH and alkaline phosphatase levels were within normal range in the two groups. No significant difference was observed between the two groups. Ashrafi showed an increase in alkaline phosphatase among $23.5 \%$ of patients (1). An increase in PTH was evidently observed in $18.5 \%$ of patients. However, mean alkaline phosphatase and PTH levels were within normal range in the two groups. Nevertheless, alkaline phosphatase level was significantly higher than PTH in the control group. This difference may be due to the issue that the statistical population consisted of children. Given that bone mineral accrued within bone during childhood and adolescence, bone metabolism increases during this period. Increased bone density continues until adulthood. Thereby, the difference can be attributed to this issue. Iham Block showed that alkaline phosphatase and PTH were within normal range (15). However, a significant increase was observed in these factors compared to the control group. Alberto Veroti showed that alkaline phosphatase and PTH were within normal range in the patients taking carbamazepine (11). Triantafilo alkaline phosphatase and PTH were in the normal range in the patients taking sodium valproate(8). Toxacahar showed that PTH was within normal range (16). Ashjani showed that PTH was within the normal range (10). No significant difference was also observed between patients and control group in terms of PHT. However, several studies reported an increase in PTH and alkaline phosphatase. Akin showed a significant increase in PTH (17). Babayigit showed that alkaline phosphatase level was significantly higher in patients compared to the control group (13). However, no significant difference in PTH level was observed between sodium valproate and carbamazepine groups. In this study, dose and length of treatment with carbamazepine had no significant difference with calcium, phosphorus and PTH levels. However, increased length of treatment with carbamazepine significantly increased alkaline phosphatase levels within normal range. Dose and length of treatment with sodium valproate had no significant relationship with bone biochemical markers. Ashrafi reported that long-term treatment with these drugs significantly increases alkaline phosphatase and PTH levels (1). In addition, increased length of treatment with anti-epileptic drugs has significantly reduced phosphorus levels. Nevertheless, a significant relationship was not found between treatment with anticonvulsants and calcium parameter. On the other hand, the largest increase in alkaline phosphatase and PTH was observed in carbamazepine group while the smallest increase in alkaline phosphatase and PTH was observed in sodium valproate group. Verotti reported no significant relationship between dose of carbamazepine and biochemical markers of bone (18). Triantafilo (8) reported no significant relationship between length and dose of sodium valproate and biochemical markers of bone. 
DXA is a non-invasive, rapid and accurate method for assessment of bone density with regard to anticonvulsants, which lead to osteoporosis (13). In this study, density of patients' bones was assessed by DXA. Reduced bone density was observed among 16 patients $(39.02 \%)$ in carbamazepine group as well as among 18 patients (43.9\%) in sodium valproate group. There was no significant difference between the two groups. Benick Zaki et al. conducted a study on adult patients who were treated with a variety of anticonvulsant drugs in terms of bone mineral density in 2012 (19). They reported 41\% cases of reduced bone density in the group taking carbamazepine and $40 \%$ cases of reduced bone density in sodium valproate group. These results are consistent with findings of this study. In this study, a significant relationship was found in mean lumbar spine bone mineral density between patients and healthy individuals in Iran. Bone density was higher in the patients than healthy individuals. However, no significant difference was observed in mean lumbar spine bone mineral density between two groups of carbamazepine and sodium valproate. In addition to genetic and hormonal factors, adequate intake of calcium, individual mobility and sunlight are effective in bone mass. Increased bone mineral density in the patients compared to healthy individuals may be due to the fact that individual attitudes toward several issues such as nutrition have been improved over the past 16 years. No significant relationship was found in mean femoral bone mineral density among patients and healthy Iranian individuals. However, a significant difference was observed in mean femoral bone mineral density between the two groups of carbamazepine and sodium valproate. Femoral bone mineral density was significantly lower among the patients taking carbamazepine than Iranian healthy individuals. Moreover, femoral bone mineral density was significantly higher among the patients taking sodium valproate than Iranian healthy individuals. Several studies were conducted on the impact of these drugs on bone density. Akin et al. conducted a study on 53 children treated with carbamazepine and sodium valproate for more than a year in 1995 (17). They reported that carbamazepine and sodium valproate had no effect on bone density. The difference may be attributed to the short length of treatment (one year) in the former study. In our study, the length of treatment was at least 2 years. However, the difference in age of patients and the time difference cannot be neglected. Arbayat Alti et al. reported no significant difference in bone density of 36 children treated with carbamazepine and sodium valproate and the control group in 2000 (20). However, Babayigit et al.(13) reported that carbamazepine and sodium valproate significantly reduced bone density. Triantafilo et al. showed that $24 \%$ of osteogenic cases were due to monotherapy with valproate sodium among adults (8). Mean lumbar bone mineral density did not show significant differences in the two groups treated with carbamazepine and sodium valproate. Femoral bone densitometry in patients taking carbamazepine was more significantly reduced than the patients taking sodium valproate. El Hajj Fuelihan (21) showed that hip and lumbar bone mineral density (T. score) was significantly lower in the patients treated with the antiepileptic drug, which amplifies P450 cytochrome enzyme (carbamazepine) compared to the group treated with the anti-seizure drug, which inhibits P450 cytochrome enzyme (sodium valproate). Acoyte (22) studied monotherapeutic effects of sodium valproate and carbamazepine on femoral bone mineral density of 7 to 15 year old children in 2004. Femoral bone density in the children taking sodium valproate was significantly less than the children taking sodium valproate. The difference between results was due to age, sample size, etc.

Reduced density was not significantly associated with length of treatment in the carbamazepine group. However, increased length of treatment significantly reduced mean femoral and lumbar bone density as well as T. score in sodium valproate group. Babayigit et al.(13) showed that length of treatment with carbamazepine and sodium valproate did not significantly reduce bone density. Triantafilo (8) evaluated monotherapy of sodium valproate and showed that length of treatment with sodium valproate did not significantly reduce bone mineral density. Sheet et al.(23) determined that increased length of treatment with sodium valproate decreases bone density. No significant relationship was found between dose of medication and decreased bone density. Different doses of carbamazepine did not significantly decreased bone mineral density, which was also confirmed by Babayigit (13). Different doses of sodium valproate significantly reduced femoral bone mineral density and $\mathrm{T}$-score. Bone density increased with increasing dose. Babayigit (13) and Triantafilo (8) found no significant relationship between dose of sodium valproate and decreased bone mineral density. However, the number of patients was not equal when less than or above $400 \mathrm{mg}$ dose of sodium valproate was used. Thereby, dose-dependent results might not be reliable.

\section{Conclusions}

Carbamazepine and sodium valproate effectively treat epilepsy. According to the study, carbamazepine is more destructive than sodium valproate among adult patients at both levels of bone biochemical markers and bone mineral density (femoral bone mineral density). Therefore, it is recommended that sodium valproate be used to treat epilep sy among adults in cases of equal conditions. In long-term treatment with these drugs, periodic monitoring of biochemical markers of bone and bone densitometry are also recommended. It is also recommended that calcium supplements and calcium-rich diet be observed from the beginning of treatment with these drugs. 


\section{Acknowledgments:}

We thank the library of Shahid Sadoughi University of Medical Sciences for their help in literature review, and all the patients and neurology ward nurses who helped us to conduct this study.

\section{Conflict of Interest:}

There is no conflict of interest to be declared.

Authors' contributions:

All authors contributed to this project and article equally. All authors read and approved the final manuscript.

\section{References:}

1) Ashrafi M, Khoshhal F, Rabani A, Salajegheh N, Nasab AM, Shams S, et al. Study of Antiepileptic Drugs effects on bone metabolism. Iranian Journal of Pediatrics. 2005;15(4):347-52.

2) Eizadi-Mood N, Yaraghi A, Gheshlaghi F, Mogiri R. Poison-induced seizures in 66 patients: Causes, treatments and outcomes. Tehran University Medical Journal. 2008;66(3):214-20.

3) Beattie K, Phadke G, Novakovic J. Lamotrigine. Profiles of drug substances, excipients, and related methodology. 2012;37:245-85. doi: 10.1016/B978-0-12-397220-0.00006-4, PMid: 22469320

4) Pack AM, Morrell MJ. Epilepsy and bone health in adults. Epilepsy \& Behavior. 2004;5:24-9. doi: 10.1016/j.yebeh.2003.11.029, PMid: 15123008

5) Petty SJ, O'brien T, Wark J. Anti-epileptic medication and bone health. Osteoporosis international. 2007;18(2):129-42. doi: 10.1007/s00198-006-0185-z, PMid: 17091219

6) Valsamis HA, Arora SK, Labban B, McFarlane SI. Antiepileptic drugs and bone metabolism. Nutrition \& metabolism. 2006;3(1):36. doi: 10.1186/1743-7075-3-36, PMid: 16956398, PMCid: PMC1586194

7) Pack A. Bone health in people with epilepsy: is it impaired and what are the risk factors? Seizure. 2008;17(2):181-6. doi: 10.1016/j.seizure.2007.11.020, PMid: 18187347

8) Triantafyllou N, Lambrinoudaki I, Armeni E, Evangelopoulos E-M, Boufidou F, Antoniou A, et al. Effect of long-term valproate monotherapy on bone mineral density in adults with epilepsy. Journal of the neurological sciences. 2010;290(1):131-4. doi: 10.1016/j.jns.2009.12.015, PMid: 20056251

9) Pellock JM. Carbamazepine side effects in children and adults. Epilepsia. 1987;28(s3):S64-S70. doi: 10.1111/j.1528-1157.1987.tb05780.x, PMid: 2961558

10) Ashjazadeh N, Zamani A, Pourjafar M, Omrani GR. Bone density of ambulatory adult patients receiving long-term anticonvulsant drug therapy. Arch Iran Med. 2009;12(6):550-4. PMid: 19877746

11) Verrotti A, Coppola G, Parisi P, Mohn A, Chiarelli F. Bone and calcium metabolism and antiepileptic drugs. Clinical neurology and neurosurgery. 2010;112(1):1-10. doi: 10.1016/j.clineuro.2009.10.011, PMid: 19913352

12) Sheth RD. Bone health in pediatric epilepsy. Epilepsy \& Behavior. 2004;5:30-5. doi: 10.1016/j.yebeh.2003.11.025, PMid: 15123009

13) Babayigit A, Dirik E, Bober E, Cakmakc1 H. Adverse effects of antiepileptic drugs on bone mineral density. Pediatric neurology. 2006;35(3):177-81. doi: 10.1016/j.pediatrneurol.2006.03.004, PMid: 16939856

14) Drezner MK. Treatment of anticonvulsant drug-induced bone disease. Epilepsy \& Behavior. 2004;5:41-7. doi: 10.1016/j.yebeh.2003.11.028, PMid: 15123011

15) Boluk A, Guzelipek M, Savlı H, Temel I, Ozışık HI, Kaygusuz A. The effect of valproate on bone mineral density in adult epileptic patients. Pharmacological research. 2004;50(1):93-7. doi: 10.1016/j.phrs.2003.11.011, PMid: 15082034

16) Tsukahara H, Kimura K, Todoroki Y, Ohshima Y, Hiraoka M, Shigematsu Y, et al. Bone mineral status in ambulatory pediatric patients on long - term anti - epileptic drug therapy. Pediatrics international. 2002;44(3):247-53. doi: 10.1046/j.1442-200X.2002.01561.x, PMid: 11982890

17) 1dvan Akın R, Okutan V, Sarıcı Ü, Altunbaş A, Gökçay E. Evaluation of bone mineral density in children receiving antiepileptic drugs. Pediatric neurology. 1998;19(2):129-31. doi: 10.1016/S0887-8994(98)000393

18) Verrotti A, Greco R, Latini G, Morgese G, Chiarelli F. Increased bone turnover in prepubertal, pubertal, and postpubertal patients receiving carbamazepine. Epilepsia. 2002;43(12):1488-92. doi: 10.1046/j.15281157.2002.13002.x, PMid: 12460249 
19) Beniczky SA, Viken J, Jensen LT, Andersen NB. Bone mineral density in adult patients treated with various antiepileptic drugs. Seizure. 2012;21(6):471-2. doi: 10.1016/j.seizure.2012.04.002, PMid: 22541979

20) Erbayat Altay E, Serdaroğlu A, Tümer L, Gücüyener K, Hasanoğlu A. Evaluation of bone mineral metabolism in children receiving carbamazepine and valproic acid. Journal of Pediatric Endocrinology and Metabolism. 2000;13(7):933-40. doi: 10.1515/JPEM.2000.13.7.933, PMid: 10968482

21) Fuleihan GE-H, Dib L, Yamout B, Sawaya R, Mikati MA. Predictors of bone density in ambulatory patients on antiepileptic drugs. Bone. 2008;43(1):149-55. doi: 10.1016/j.bone.2008.03.002, PMid: 18467202

22) Ecevit C, Aydogan A, Kavakli T, Altinoz S. Effect of carbamazepine and valproate on bone mineral density. Pediatr Neurol. 2004;31(4):279-82. doi: 10.1016/j.pediatrneurol.2004.03.021, PMid: 15464641

23) Sheth RD, Wesolowski CA, Jacob J, Penney S, Hobbs GR, Riggs JE, et al. Effect of carbamazepine and valproate on bone mineral density. The Journal of pediatrics. 1995;127(2):256-62. doi: 10.1016/S00223476(95)70304-7 